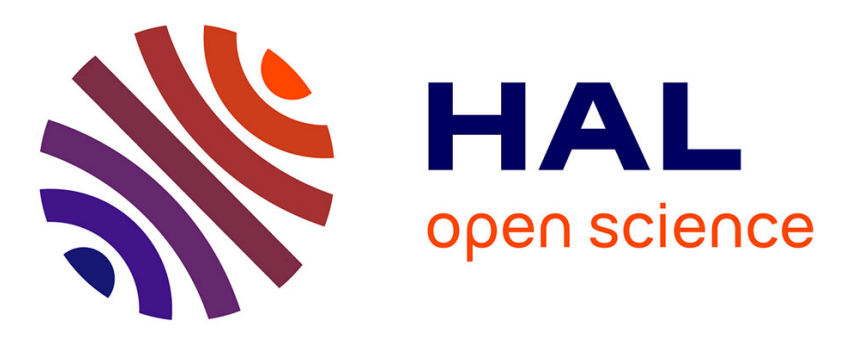

\title{
Disclosing Pt-Bimetallic Alloy Nanoparticle Surface Lattice Distortion with Electrochemical Probes
}

Raphaël Chattot, Isaac Martens, Marion Scohy, Juan Herranz, Jakub Drnec, Frédéric Maillard, Laetitia Dubau

\section{- To cite this version:}

Raphaël Chattot, Isaac Martens, Marion Scohy, Juan Herranz, Jakub Drnec, et al.. Disclosing PtBimetallic Alloy Nanoparticle Surface Lattice Distortion with Electrochemical Probes. ACS Energy Letters, 2019, 5 (1), pp.162-169. 10.1021/acsenergylett.9b02287 . hal-02931373

\section{HAL Id: hal-02931373 https://hal.science/hal-02931373}

Submitted on 6 Sep 2020

HAL is a multi-disciplinary open access archive for the deposit and dissemination of scientific research documents, whether they are published or not. The documents may come from teaching and research institutions in France or abroad, or from public or private research centers.
L'archive ouverte pluridisciplinaire HAL, est destinée au dépôt et à la diffusion de documents scientifiques de niveau recherche, publiés ou non, émanant des établissements d'enseignement et de recherche français ou étrangers, des laboratoires publics ou privés. 
Subscriber access provided by BIBCNRS INC

\section{Letter}

\section{Disclosing Pt-Bimetallic Alloy Nanoparticle Surface Lattice Distortion with Electrochemical Probes}

Raphaël Chattot, Isaac Martens, Marion Scohy, Juan

Herranz, Jakub Drnec, Frédéric Maillard, and Laetitia Dubau

ACS Energy Lett., Just Accepted Manuscript • DOI: 10.1021/acsenergylett.9b02287 • Publication Date (Web): 18 Nov 2019

Downloaded from pubs.acs.org on November 18, 2019

\section{Just Accepted}

"Just Accepted" manuscripts have been peer-reviewed and accepted for publication. They are posted online prior to technical editing, formatting for publication and author proofing. The American Chemical Society provides "Just Accepted" as a service to the research community to expedite the dissemination of scientific material as soon as possible after acceptance. "Just Accepted" manuscripts appear in full in PDF format accompanied by an HTML abstract. "Just Accepted" manuscripts have been fully peer reviewed, but should not be considered the official version of record. They are citable by the Digital Object Identifier (DOIß). "Just Accepted" is an optional service offered to authors. Therefore, the "Just Accepted" Web site may not include all articles that will be published in the journal. After a manuscript is technically edited and formatted, it will be removed from the "Just Accepted" Web site and published as an ASAP article. Note that technical editing may introduce minor changes to the manuscript text and/or graphics which could affect content, and all legal disclaimers and ethical guidelines that apply to the journal pertain. ACS cannot be held responsible for errors or consequences arising from the use of information contained in these "Just Accepted" manuscripts. 


\title{
Disclosing Pt-Bimetallic Alloy Nanoparticle
}

\section{Surface Lattice Distortion with Electrochemical}

\section{Probes}

\author{
Raphaël Chattot 1, 2, ", Isaac Martens ${ }^{2}$, Marion Scohy ${ }^{1}$, Juan Herranz ${ }^{3}$, Jakub Drnec \\ 2, Frédéric Maillard ${ }^{1}$ and Laetitia Dubau ${ }^{1, *}$.
}

\author{
${ }^{1}$ Univ. Grenoble Alpes, CNRS, Grenoble INP $\perp$, Univ. Savoie Mont Blanc, LEPMI, 38000 \\ Grenoble, France
}

\begin{abstract}
${ }^{2}$ ESRF-The European Synchrotron, ID 31 Beamline, 38043 Grenoble, France
${ }^{3}$ Electrochemistry Laboratory, Paul Scherrer Institut, 5232 Villigen, Switzerland
\end{abstract}


*e-mail: (RC) raphael.chattot@grenoble-inp.org; (LD) laetitia.dubau@lepmi.grenoble-inp.fr

$\perp$ Institute of Engineering Univ. Grenoble Alpes

Structural defects are of significant importance in (electro)catalysis, as they provide sites of unusually high activity that find applications in many key electrochemical processes. However, tools to characterize surface defects remain scarce and complex, especially for nanocatalysts where classical methods such as transmission electron microscopy or X-ray scattering are limited in their ability to probe the structure and distribution of the active surface sites. Herein, we show that the ratio between the $\mathrm{CO}_{\text {ads }}$ stripping charge $\left(Q_{\mathrm{co}}\right)$ and the charge required to desorb under-potentially deposited $\mathrm{H}$ atoms $\left(Q_{\mathrm{H}}\right)$ in structurally-disordered Pt-based nanocatalysts scales almost linearly with the Surface Distortion descriptor obtained via advanced physical methods. This trend is valid in both rotating disk electrode configuration and in a real fuel cell device, thus providing the scientific community with a powerful and versatile approach for semi-quantitative estimation of the surface lattice distortion in Pt-based catalysts without the need for exhaustive structural characterization. 


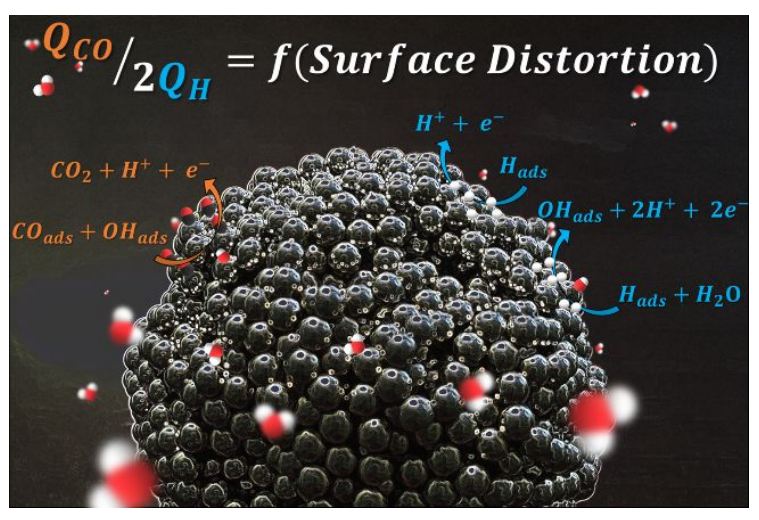

19

21 
The past decade of extensive research on well-defined, extended bimetallic surfaces has defined the main strategies towards the design of more efficient nanocatalysts for key electrochemical processes such as those encountered in proton-exchange membrane fuel cells (PEMFCs) and water electrolysers (PEMWEs) ${ }^{1}$. In particular, 'PtM-skin' surfaces (where $M$ is a transition metal) have received remarkable attention due to their exceptional activity towards the oxygen reduction reaction (ORR) relative to pure $\mathrm{Pt}^{2}$, which stems from their weakened interactions with $\mathrm{H}$ and oxygenated adsorbates $(\mathrm{O}, \mathrm{OH} \text { and } \mathrm{OOH} \text { species })^{3}$. These peculiar adsorption properties can be probed through cyclic voltammetry (CV) experiments by calculating the integrated charges for adsorption/desorption of under-potentially deposited hydrogen $\left(\mathrm{H}_{\mathrm{UPD}}\right)$ and the electrooxidation of a pre-adsorbed $\mathrm{CO}$ monolayer (so-called $\mathrm{CO}_{\text {ads }}$ stripping experiment). The ratio of these integrated charges, $Q_{\mathrm{CO}} / 2 Q_{\mathrm{H}}$, is close to 1 for conventional Pt surfaces ${ }^{4}$ but reaches 1.5 for 'Pt-skin'-type surfaces ${ }^{5}$.

Unlike such model catalyst systems, many recently proposed electrocatalysts such as PtM or IrM aerogels ${ }^{6,7}$, jagged $\mathrm{Pt}^{8}$ and PtNi nanowires ${ }^{9}$, mesostructured thin films ${ }^{10}$, porous/hollow PtM ${ }^{11-13}$ or PtM sponge ${ }^{14}$ nanoparticles feature structurally-defective surfaces. Such structurally-disordered nanocatalysts have indeed demonstrated desirable catalytic performances for a wide range of electrochemical reactions including the ORR ${ }^{6,8-12,14-17}$, the $\mathrm{CO}_{\text {ads }}$ monolayer electrooxidation ${ }^{14,18}$, the methanol or ethanol electrooxidation ${ }^{19-22}$, and the 
hydrogen and oxygen evolution reactions ${ }^{7,23-25}$. Unlike an ideal, homogeneously packed crystal surface in which all catalytic sites are uniformly coordinated and tailored to optimize the adsorption energy of a given adsorbate, defective surfaces feature a broad distribution of catalytic site coordinations, and thus, catalytic site electronic configurations ${ }^{26}$. Consequently, independent of the nature and the structure of the required active sites for a given reaction, these sites are statistically present on defective surfaces. This multisite effect explains why a structurally-disordered surface catalyses more efficiently a larger range of catalytic reactions compared with a better structurally-ordered surface of identical composition ${ }^{19}$.

Theoretical models like the general atomic coordination theory introduced by Calle Vallejo et al. establish a powerful relation between surface defects and electrocatalytic activity ${ }^{26,27}$. However, this parameter is difficult to use in practice as it relies upon exhaustively counting the number of neighbouring atoms around each catalytic site to predict a catalyst material activity. Moreover, the ability to construct realistic computational models of practical, defective nanomaterials at the atomic scale remains challenging. Previous works have proposed experimental approaches to quantify the fraction of structural defects as an indirect estimation of this 'coordination' effect $14,18,28$, and a substantial step forward was recently achieved with the Surface Distortion (SD) descriptor ${ }^{29}$. The latter is obtained by Rietveld refinement of highenergy synchrotron wide angle X-ray scattering (WAXS) patterns and X-ray energy dispersive 
spectroscopy (X-EDS) analyses, and has proven capable to successfully capture the degree of local surface strain and rationalize the ORR activity of some of current state-of-the-art PtNi nanoalloys. However, since it is derived from bulk-sensitive techniques, the SD parameter is an indirect descriptor of the surface state for a given material, and its estimation requires combining a wide range of techniques that are sometimes only accessible in synchrotron facilities, and therefore not necessarily accessible at the laboratory scale. Other physical approaches, such as coherent X-ray diffraction ${ }^{30}$, spherical aberration-corrected (scanning) transmission electron microscopy (Cs-corrected (S)TEM) coupled with geometric phase analysis (GPA) ${ }^{31,32}$ or generalized Fourier iterative reconstruction (GENFIRE) ${ }^{33}$ provide 2D or 3D mappings of the strain field or atomic disorder at the nanoparticle level. However, these methods are also built on complex, scarce and expensive experimental setups, and provide information restricted to only few nanoparticles out of the several billions composing a catalyst. To tackle this shortcoming, in this contribution, we compare the coulometry of $\mathrm{H}_{\mathrm{UPD}}$ and $\mathrm{CO}_{\text {ads }}$ monolayer electrooxidation on a wide range of $\mathrm{Pt}$ and $\mathrm{PtNi}$ nanocatalysts and combine the observations derived from electrochemical and synchrotron X-ray based physical characterization techniques. Our results show that the $Q_{\mathrm{CO}} / 2 Q_{\mathrm{H}}$ ratio scales almost linearly with the physical SD descriptor and represents a unique electrochemical adsorption fingerprint of 'distorted' surfaces. The practical applicability of this ratio as a global and surface-sensitive 
diagnostic tool is then demonstrated by probing the structure of the catalysts both in liquid electrolyte and in an operational PEMFC device.

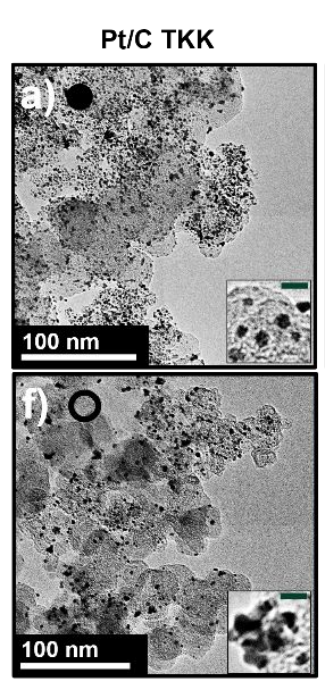

A-Pt/C

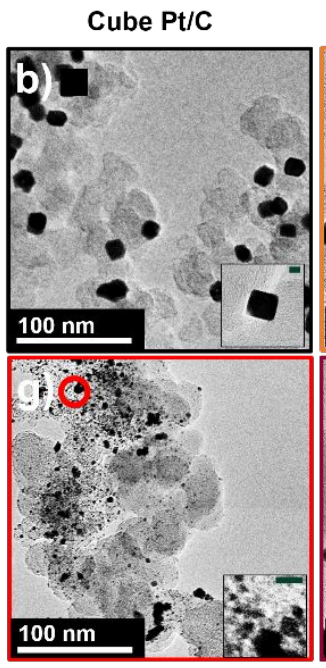

A-PtNi/C
Sphere PtNi/C

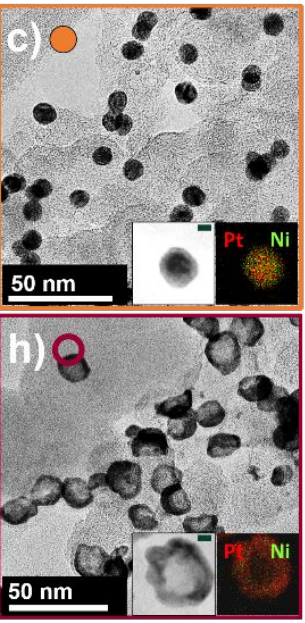

Hollow PtNi/C
Cube PtNi/C

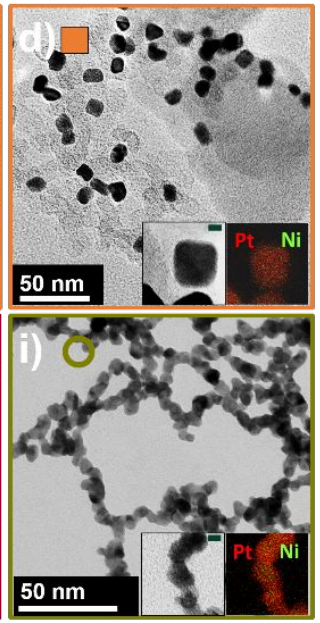

Aerogel PtNi
Octahedron PtNi/C

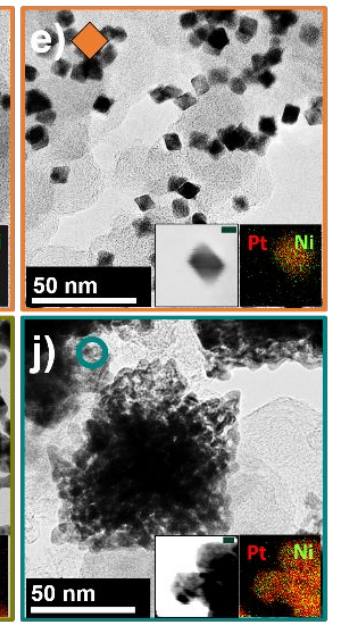

Sponge PtNi/C
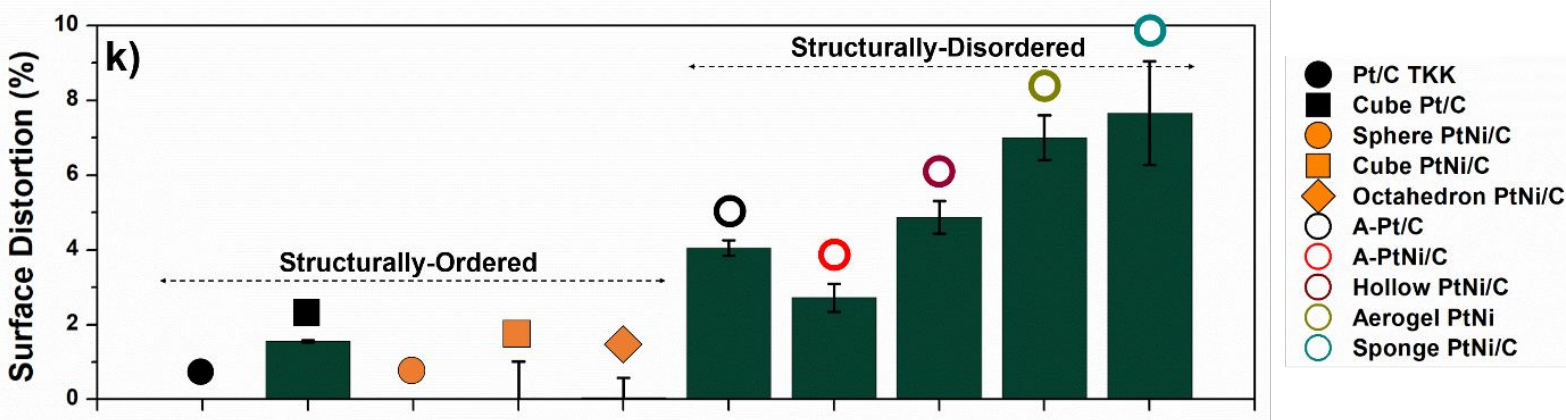

Figure 1. Morphology and structure of the nanocatalysts used in this study. TEM images of a)-e) structurally-ordered and f)-j) structurally-disordered catalysts, along with k) the corresponding Surface Distortion (SD) values derived from Rietveld refinement of synchrotron WAXS patterns. The error bars refer to the standard deviations. Inserts in a), b), f) and g) show high magnification TEM images and inserts in c), d), e), h), i) and j) display STEM/X-EDS elemental maps in which Pt and Ni atoms are displayed in red/green, respectively. In the inserts, the scale bars stand for $5 \mathrm{~nm}$. 
Fig. 1.a-1.j shows transmission electron microscopy (TEM) and scanning electron transmission microscopy coupled with X-ray energy dispersive spectroscopy (STEM/X-EDS) images of the ten nanostructures used in this work. Specifically, Fig. 1.a-1.e features the images acquired on structurally-ordered materials composed of isolated, monocrystalline $\mathrm{Pt}$ and/or PtNi nanoparticles featuring different nanoparticle shapes, sizes and chemical compositions: spherical Pt (Pt/C TKK), cubic Pt (Cube Pt/C), spherical PtNi (Sphere PtNi/C), and cubic and octahedral PtNi (Cube vs. Octahedron PtNi/C, respectively). Complementarily, Fig. 1.f-1.j displays the images obtained for structurally-disordered materials composed of partially aggregated $\mathrm{Pt}$ and/or PtNi nanoparticles (A-Pt/C and A-PtNi/C respectively) and multi-grained PtNi superstructures (Hollow PtNi/C, Aerogel PtNi and Sponge PtNi/C). More details about the crystallites/nanoparticles sizes and chemical compositions of the various electrocatalysts can be found in Table S1 of the Supplementary Information.

As discussed in a previous report ${ }^{29}$, the SD values obtained by Rietveld refinement of synchrotron WAXS patterns and derived from the values of microstrain ( viz. local deformation of a crystal lattice) provide insights into the degree of surface defectiveness of Pt and PtNi nanocatalysts. Low SD values are characteristic of homogeneously packed surfaces, whereas high SD values reflect surface disorder, such as that created by acid leaching of a nanoalloy or by aggregation (formation of grain boundaries). Fig. 1.k shows that all structurally-ordered 
catalysts feature only slightly positive or null SD values, suggesting that their surfaces are homogeneously packed, in agreement with the observations derived from TEM images (note that according to the SD value, the Cube Pt/C sample may feature some degree of aggregation). In contrast, the highest SD values are found for the structurally-disordered catalysts. Now, despite the ability of the SD descriptor to capture the degree of defectiveness of a given bimetallic catalyst, determining accurate $S D$ values requires the use of a high-energy synchrotron beamline. Unfortunately, the limited number of such facilities worldwide and their limited access compromise the widespread use of this descriptor in conventional electrochemistry laboratories, whereby the consideration of a catalyst surface disorder is consequently largely overlooked.

To overcome this issue, one may propose the use of $\mathrm{CO}_{\mathrm{ads}}$ monolayer oxidation as a convenient and direct molecular probe to investigate the fine surface structure of PtM nanomaterials, since their particles composition ${ }^{34}$, size ${ }^{35}$, aggregation ${ }^{36}$, and surface crystallography ${ }^{37}$ are known to influence this reaction kinetics. Following this approach, the background-subtracted $\mathrm{CO}_{\mathrm{ads}}$ stripping voltammograms recorded on structurally-ordered nanoparticles of all the catalysts presented above and $\mathrm{Pt}(111)$ and $\mathrm{Pt}(100)$ single crystals are displayed in Fig. 2.a. It is clear that variations of the shape and chemical composition of the monocrystalline samples result in a pronounced shift of the $\mathrm{CO}_{\text {ads }}$ stripping oxidation peak 
towards lower potentials compared to the Pt/C TKK reference. For a fixed chemical composition, the $\mathrm{CO}_{\text {ads }}$ electrooxidation onset potential increases in the order $\operatorname{Pt}(111)<\operatorname{Pt}(100)$ $<<\mathrm{Pt}($ poly-oriented $)$ and $\mathrm{PtNi}(111)<\mathrm{PtNi}(100) \cong \mathrm{PtNi}($ poly-oriented $)$ for pure $\mathrm{Pt}$ and $\mathrm{PtNi}$ nanoparticles, respectively. Similarly, for a given crystallographic facet orientation, alloying $\mathrm{Ni}$ with $\mathrm{Pt}$ results in a pronounced decrease of the onset potential for $\mathrm{CO}_{\mathrm{ads}}$ monolayer electrooxidation (likely due to a decrease of the CO binding energy), in agreement with previous reports ${ }^{5,38}$. 

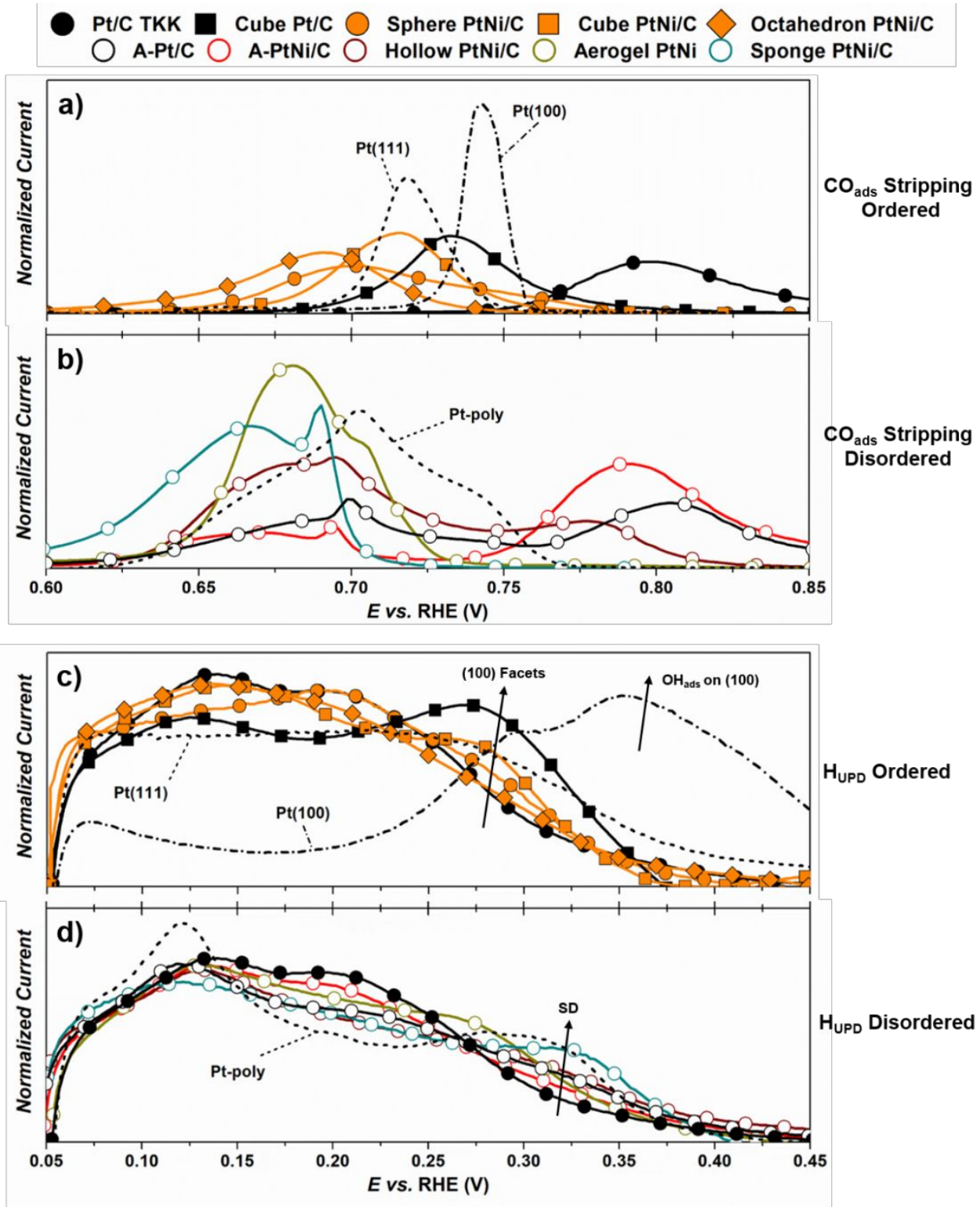

Figure 2. Background-subtracted $\mathrm{CO}_{a d s}$ stripping and $\mathrm{H}_{\text {ads }}$ desorption voltammograms recorded on structurally-ordered and structurally-disordered Pt and PtNi nanocatalysts. The $\mathrm{CO}_{a d s}$ stripping curves are shown in a) and b) and the $H_{\text {ads }}$ desorption curves in c) and d) for structurally-ordered and structurally-disordered catalysts, respectively. All curves were recorded in Ar-saturated $0.1 \mathrm{M}$ $\mathrm{HClO}_{4}$ electrolyte at a potential sweep rate of $20 \mathrm{mV} \mathrm{s}^{-1}$. The labelled dotted lines represent cyclic voltammograms of extended Pt surfaces. The currents in a)-b) and c)-d) are normalized by the $C O_{a d s}$ electrooxidation coulometry $\left(Q_{C O}\right)$ and the $H_{a d s}$ desorption charge coulometry $\left(Q_{H}\right)$, respectively. 
Structurally-disordered catalysts (Fig. 2.b) also display a pronounced shift of the $\mathrm{CO}_{\mathrm{ads}}$ monolayer electrooxidation peak towards lower potentials with respect to the polycrystalline platinum (Pt-poly) surface. However, this phenomenon is mitigated for partially nanoparticles, i.e. those presenting a fraction of monocrystalline particles (A-Pt/C, A-PtNi/C and Hollow $\mathrm{PtNi} / \mathrm{C})$, for which two main $\mathrm{CO}_{\mathrm{ads}}$ stripping peaks are noticed: the first at low potential $(0.60<$ $E<0.73 \vee v s$. RHE), followed by a high potential peak ( $E>0.73 \vee v s$. RHE). Interestingly, this observation is independent of the catalysts chemical composition, since it is observed for both pure and bimetallic nanocatalysts. The low potential contribution is preponderant for Aerogel $\mathrm{PtNi}$ and Sponge PtNi/C, in which all nanocrystallites are likely connected by grain boundaries. Nonetheless, it is clear from Fig. 2.a-2.b that isolating a particular morphological parameter such as the surface defectiveness from its synergetic interactions with others (particle size, surface composition or crystallography) on the basis of a potential shift in $\mathrm{CO}_{\text {ads }}$ stripping is an arduous, if not impossible, task. Moreover, fundamental questions such as the nature of preferential adsorption sites for $\mathrm{CO}_{\mathrm{ads}}$, its modes of binding (linear, bridge, multi-bonded), the $\mathrm{CO}_{\text {ads }}$ coverage, the mobility of $\mathrm{CO}_{\mathrm{ads}}$ molecules on the surface, or the nature of the active sites are still under debate in the literature ${ }^{39,40}$.

Another well-known chemical probe in electrocatalysis is adsorbed hydrogen $\left(\mathrm{H}_{\text {ads }}\right)$. It is widely accepted ${ }^{3,5,26}$ that weakened interactions between Pt and small adsorbates, such as $\mathrm{H}_{\text {ads, }}$ 
result from the modified electronic structure of $\mathrm{Pt}$, the latter being directly correlated to the coordination number of the catalytic site. Thus, the results of the CV experiments in the $\mathrm{H}_{\mathrm{UPD}}$ region are plotted in Figs. 2c and 2.d for structurally-ordered and -disordered catalysts, respectively (note that the measurements made on the Pt/C TKK catalyst are shown in both plots). Notably, all nanocatalysts feature higher $\mathrm{H}_{\text {ads }}$ desorption currents at potential $E<0.10$ V vs. RHE when compared to the Cube and Pt/C TKK materials. This agrees with earlier reports suggesting that strained surfaces feature a lower affinity for small adsorbates such as $\mathrm{H}_{\mathrm{ads}}$ or $\mathrm{OH}_{\mathrm{ads}}{ }^{41,42}$; resulting in improved ORR activity, as experimentally observed especially for the Octahedron PtNi/C (Fig. 2.c) and the Sponge PtNi/C catalysts (Fig. 2.d and Table S2).

Despite their higher ORR activity, many electrocatalysts show a similar or even increased $\mathrm{H}_{\text {ads }}$ desorption current density relative to the Pt/C TKK material at higher potentials $(E>0.30 \mathrm{~V} v s$. RHE), suggesting the presence of catalytic sites that bind $\mathrm{H}_{\mathrm{ads}}$ (and by extension $\mathrm{OH}_{\text {ads }}$ ) more strongly than pure Pt/C. This is easily understandable for cubic-shaped nanoparticles (Cube $\mathrm{Pt} / \mathrm{C}$ and Cube PtNi/C in Fig. 2.c), since studies on single crystals ${ }^{43}$ have attributed the current between 0.20 and $0.30 \mathrm{~V}$ vs. RHE to $H_{\text {ads }}$ desorption from the (100) facets (see the $H_{\text {ads }}$ desorption profile of $\mathrm{Pt}(100)$ in Fig. $2 \mathrm{c})$. However, the feature observed at higher electrode potentials ( $E>0.30 \mathrm{~V} v s$. RHE) for all the structurally-disordered catalysts in Fig. 2.d is striking. This high potential contribution also appears after partial agglomeration of a pure Pt/C catalyst 
(see A-Pt/C compared to Pt/C TKK): thus, it is very unlikely that this current is related to desorption of $\mathrm{H}_{\mathrm{ads}}$ from (100) facets (or any other preferential crystallographic orientation), since nanocrystallites for this class of catalysts do not feature any defined shape or faceting according to the above TEM observations.

To gain more insights into the electrochemical processes occurring at $E>0.30 \mathrm{~V} v s$. RHE, we calculated the ratio of the $\mathrm{CO}_{\text {ads }}$ stripping charge $\left(Q_{\mathrm{CO}}\right)$ to the $\mathrm{H}_{\mathrm{UPD}}$ charge $\left(Q_{\mathrm{H}}\right)$ for all nanocatalysts. The results presented in Table S2 and Fig. 3 (large symbols) show that $Q_{\mathrm{CO}} / 2 Q_{\mathrm{H}}$ values $\geq 0.94$ are found for the structurally-ordered catalysts (featuring SD values close to 0 ), whereas all the defective catalysts (with high SD values) feature extremely low $Q_{\mathrm{Co}} / 2 Q_{\mathrm{H}}$ ratios comprised between 0.75 and 0.92 . Consequently, the results presented in Fig. 3 suggest that low $Q_{\mathrm{CO}} / 2 Q_{\mathrm{H}}$ values constitute a fingerprint of what we term 'Pt-distorted' surfaces (i.e. surfaces featuring local strain). Moreover, the nearly linear relation between the $Q_{\mathrm{CO}} / 2 Q_{H}$ ratio and the $\mathrm{SD}$ descriptor in the range $0<\mathrm{SD}<8$ allows using this ratio to semi-quantitatively estimate a catalyst surface disorder, just as the synchrotron X-ray based SD descriptor does, yet in a much more facile and accessible way. Note also that a $Q_{\mathrm{co}} / 2 Q_{\mathrm{H}}$ boundary value of $c a .0 .94$ between disordered and ordered surface state regions is found in our experimental conditions (interpolation of the trends) and using our voltammogram integration method (state-of-the-art conditions according to Kocha, Garsany, Swider-Lyon and co-workers ${ }^{44-48}$, see in the 
Supplementary Information). This may not represent an absolute value, as indicated by the size of the error bars in Fig. 3, the latter being most likely related to the intrinsic size, shape and chemical composition heterogeneity of the nanoparticles composing the homemade and commercial practical catalysts under investigation. As also shown in Fig. 3, when our results are interpreted in light of the findings of Van Der Vliet et al. ${ }^{5}$, the $Q_{\mathrm{CO}} / 2 Q_{\mathrm{H}}$ ratio allows the identification of three surface states with increasing degree of structural ordering, from 'Ptdistorted' to 'Pt-skin', through an intermediate region attributed to 'Pt-skeleton' surfaces (i.e. featuring Pt-rich surface with possible steps but no local lattice strain nor compositional oscillations ${ }^{5}$ ). We provide extensive details on the approach used to determine the $Q_{H}$ and $Q_{\text {Co }}$ charges in the Supplementary Information. Different double-layer current or background subtraction methods may lead to biased values of the $Q_{\mathrm{CO}} / 2 Q_{\mathrm{H}}$ ratio. Mayrhofer et al. ${ }^{49}$ and Schulenburg et al. ${ }^{50}$ describe how to correct for these factors and obtain accurate values of $Q_{H}$ and $Q_{\mathrm{CO}}$. If these best practices are not rigorously followed, $Q_{\mathrm{CO}} / 2 Q_{\mathrm{H}}$ ratio above 1 would likely be obtained for distorted surfaces $8,51,52$.

For the sake of demonstrating the broader fundamental and technological significance of this new electrochemical descriptor, membrane electrodes assemblies (MEAs) were prepared and tested in a PEMFC device (details about MEA preparation and fuel cell tests are available in the Supplementary Information), and the corresponding $Q_{\mathrm{CO}} / 2 Q_{\mathrm{H}}$ values derived in this 
configuration are included in Fig. 3 (small symbols). It is clear that the $Q_{\mathrm{CO}} / 2 Q_{H}$ ratios and their corresponding relation to the WAXS-derived SD values vary similarly in the aqueous RDE and polymer electrolyte fuel cell environments (additionally implying that the $Q_{\mathrm{CO}} / 2 Q_{\mathrm{H}}$ is anionindependent, see Figures S5-S6): this demonstrates that the $Q_{\mathrm{CO}} / 2 Q_{H}$ ratio provides a simple, non-destructive (Fig. S7) and non-invasive tool to probe the surface defectiveness of a given catalyst, and opens new doors for in situ PEMFC catalyst characterization. Note that we also prove the $Q_{\mathrm{CO}} / 2 Q_{\mathrm{H}}$ ratio able to capture the structural changes occurring on the nanoparticles surface after $22 \mathrm{~h}$ acidic treatment in $1 \mathrm{M} \mathrm{H}_{2} \mathrm{SO}_{4}$ (see Fig. S8). 


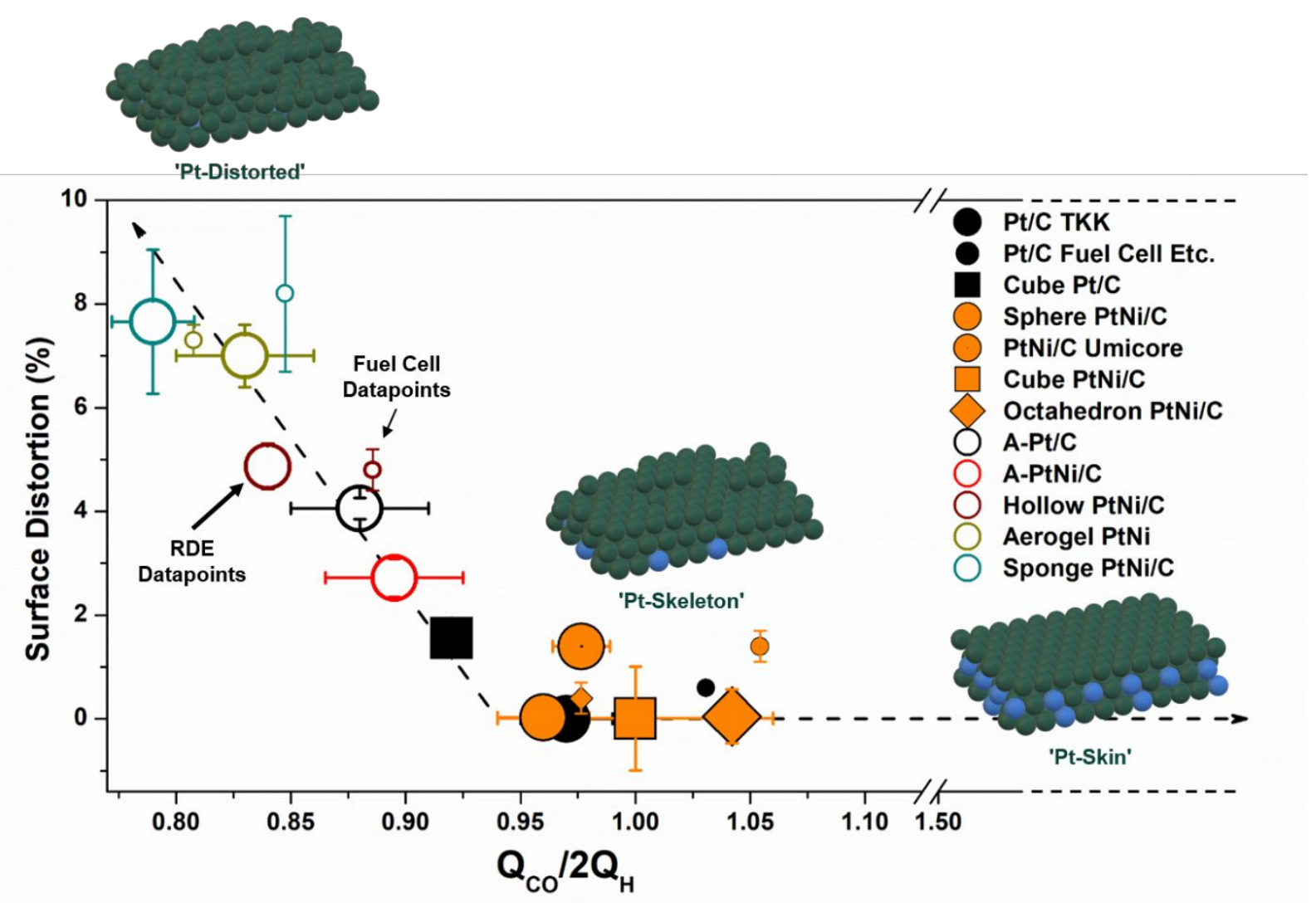

Figure 3. Probing surface distortion using the $Q_{C O} / 2 Q_{H}$ ratio in both liquid electrolyte and in a PEM fuel cell device. Whereas $Q_{C O} / 2 Q_{H} \geq 1.5$ values indicate the presence of a 'Pt-skin' surface ${ }^{5}$, $Q_{C O} / 2 Q_{H}$ values $<0.94$ reflect 'Pt-distorted' surfaces. The region in-between those two is usually assigned to 'Pt-skeleton' surfaces ${ }^{5}$. The $Q_{C O}$ and $Q_{H}$ values were extracted from $\mathrm{CO}_{\text {ads }}$ stripping voltammograms measured in a $5 \mathrm{~cm}^{2}$ PEM fuel cell (small symbols) or in $0.1 \mathrm{M} \mathrm{HClO}_{4}$ (large symbols) and the SD values using ex situ synchrotron WAXS patterns and the methodology formerly introduced in Ref. ${ }^{29}$. The error bars represent the standard deviations of these quantities. Note that some of the PEM fuel cell measurements were performed on materials' batches different from those used for the RDE tests. All measurements have been performed at $25^{\circ} \mathrm{C}$. The inset surfaces drawings depict Pt and Ni atoms as green and blue spheres, respectively. The dashed lines serve as guides to the eye. 
We now discuss the possible origin of the $Q_{\mathrm{CO}} / 2 Q_{H}$ ratio changes on structurally-ordered $v s$. distorted surfaces. Although this ratio depends on both $\mathrm{H}_{\mathrm{ads}}$ and $\mathrm{CO}_{\text {ads }}$ molecular coverage 53 (which can be affected by strain and ligand effects ${ }^{41}$ ), since the trend in $\mathrm{H}$ adsorption was reported to correlate well with that of $\mathrm{CO}$ on various $\mathrm{M} / \mathrm{Pt}(111)$ model systems ${ }^{38,54,55}$ (excluding the particular case of 'Pt-skin'), we believe that our results support the hypothesis proposed by Marichev et al. ${ }^{56}$, and further advanced by Van Der Niet et al. ${ }^{57}$. These authors claim that $\mathrm{H}_{\mathrm{ads}}$ species and $\mathrm{OH}_{\mathrm{ads}}$ adsorbates co-exist in the potential region $E<0.40 \mathrm{~V} v s$. RHE on non-(111) Pt surfaces even in acidic media (note that this was also suggested earlier by Marković et al. ${ }^{43}$ for alkaline media). As summarized in a recent perspective from Janik et al. ${ }^{58}$, experiments on flat and stepped single crystal surfaces such as infrared spectroscopy (IRAS) ${ }^{59}$ and carbon monoxide displacement studies ${ }^{60}$, as well as density-functional theory calculations, suggest that $\mathrm{H}_{\text {ads }}$ species can be displaced by $\mathrm{OH}_{\text {ads }}$ in the $\mathrm{H}_{\text {UPD }}$ region, following an electrochemical reaction of the type:

$$
\mathrm{Pt}-\mathrm{H}_{\mathrm{ads}}+\mathrm{H}_{2} \mathrm{O} \leftrightarrow \mathrm{Pt}-\mathrm{OH}_{\mathrm{ads}}+2 \mathrm{H}^{+}+2 \mathrm{e}^{-}
$$

The exchange mechanism of Eq. 1 predicts a charge transfer of 2 electrons per adsorbed $\mathrm{H}$ with regards to the only electron involved in the usual proton adsorption/desorption mechanism formulated below: 


$$
\mathrm{Pt}-\mathrm{H}_{\mathrm{ads}} \leftrightarrow \mathrm{Pt}+\mathrm{H}^{+}+\mathrm{e}^{-}
$$

However, this increased charge was not significantly observed by Van Der Niet et al. ${ }^{57}$ in a series of $(n-1)(111) \times(110)$ Pt stepped surfaces with $n=3,4,5,6$ and 14. The authors attributed the overall conservation of the charge transfer to a combined decrease of $\mathrm{H}_{\text {ads }}$ coverage (and thus desorption current) and a greater likelihood of Eq. 1 to proceed at step sites. Here, the decrease of the $Q_{\mathrm{CO}} / 2 Q_{\mathrm{H}}$ ratio at a supposedly constant $\mathrm{CO}_{\text {ads }}$ coverage on distorted surfaces suggests that the previously reported ${ }^{14,18,29}$ dramatic impact of local strain on site electronic structure modification enables the increased charge transfer predicted by Eq. 1 to be monitored.

This simultaneous presence of $\mathrm{OH}_{\text {ads }}$ and $\mathrm{H}_{\text {ads }}$ species in the potential region $0.3<E<0.5 \mathrm{~V}$ vs. RHE is further supported by the results displayed in Fig. 4. Specifically, Fig. 4.a-4.c shows the progressive widening of the $\mathrm{H}_{\text {UPD }}$ region and the shift of the $\mathrm{CO}_{\text {ads }}$ oxidation onset towards lower potentials with decreasing values of $Q_{\mathrm{CO}} / 2 Q_{\mathrm{H}}$ (i.e., as the catalyst surface's defectiveness increases). Specifically focusing on the disordered Sponge PtNi/C sample, Fig. 4.d unambiguously shows that the onset of $\mathrm{CO}_{\mathrm{ads}}$ electrooxidation and the end of the $\mathrm{H}_{\mathrm{UPD}}$ desorption region overlap in the potential range $\sim 0.30<E<0.50 \mathrm{~V}$ vs. RHE. Assuming a Langmuir-Hinshelwood mechanism ${ }^{61}$ for $\mathrm{CO}_{\text {ads }}$ electrooxidation, this is evidence of $\mathrm{OH}$ adsorption below $0.40 \mathrm{~V}$ vs. RHE on such a distorted surface. However, it is important to 
emphasize that the overlapping of $Q_{H}$ and $Q_{\mathrm{CO}}$ regions in the cyclic voltammograms of the Sponge PtNi/C catalyst represents an extreme case. Indeed, a $\mathrm{CO}_{\text {ads }}$ electrooxidation onset potential higher than $0.40 \mathrm{~V} v s$. RHE (and thus without any overlap with the $\mathrm{H}_{\text {UPD }}$ ) does not exclude the presence of adsorbed $\mathrm{OH}$ species in the $\mathrm{H}_{\text {UPD }}$ potential region, since not only $\mathrm{OH}$ adsorption but also its recombination with $\mathrm{CO}_{\mathrm{ads}}$ species are needed to trigger the $\mathrm{CO}_{\mathrm{ads}}$ electrooxidation process ${ }^{27}$. A good illustration of this is the fact that on $\mathrm{Pt}(100)$ surface, $\mathrm{H}_{\mathrm{ads}}$ desorption and $\mathrm{OH}$ adsorption simultaneously occur in the potential range of $E=0.40-0.50 \mathrm{~V}$ vs. RHE ${ }^{62}$ (see the $\mathrm{Pt}(100)$ single crystal voltammogram in Fig. 2c), even if the $\mathrm{CO}_{\mathrm{ads}}$ electrooxidation onset potential is still relatively high (close to $0.72 \mathrm{~V}$ vs. RHE) on the same surface (see Fig. 2a).

Last, since the $Q_{\mathrm{CO}} / 2 Q_{\mathrm{H}}$ values are likely related to (local) variations of the $\mathrm{OH}_{\mathrm{ads}}$ binding energy, (the latter being a well-known descriptor of the ORR activity), the question of a possible correlation between $Q_{\mathrm{CO}} / 2 Q_{\mathrm{H}}$ and the ORR activity naturally arises. Although out of the scope of the present contribution, the data displayed in Fig. S9.a suggests that an inverted volcano relationship holds between the $Q_{C O} / 2 Q_{H}$ ratio and the kinetic current for the ORR of either 'purely' distorted surfaces (just as the SD does ${ }^{29}$ ), but also of structurally-ordered surfaces. However, this relation seems to vanish for 'mixed' surface state (such as that encountered on agglomerated, or acid-treated preferentially shaped nanoparticles), where structural disorder, 
strain, ligand and/or ensemble effect(s) synergistically control the ORR specific activity (Fig.

S9.b).
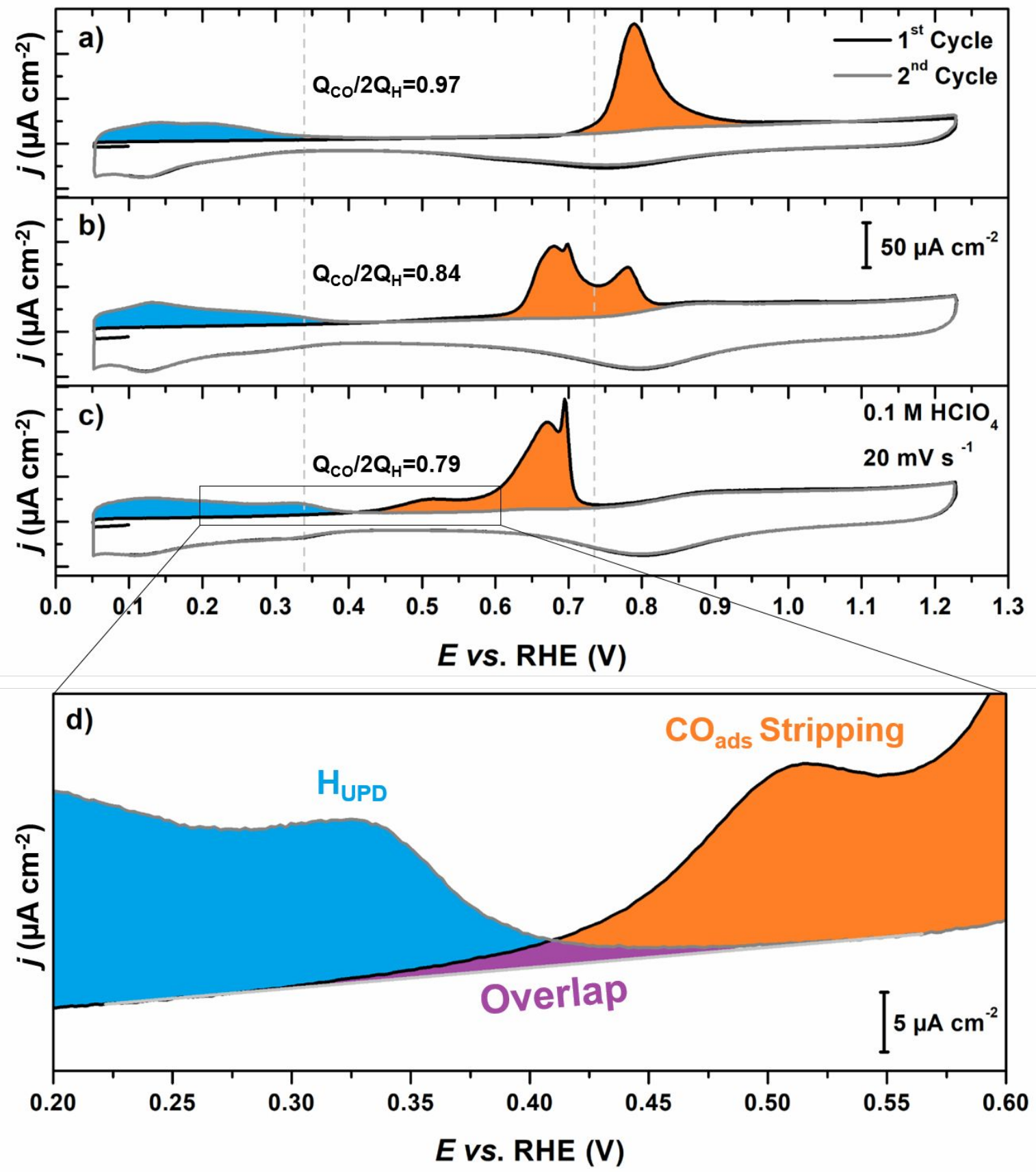

Figure 4. Influence of surface distortion on the shape of base and $\mathrm{CO}_{a d s}$ stripping voltammograms.

First and second cycles of the $\mathrm{CO}_{a d s}$ stripping experiment recorded in Ar-saturated $0.1 \mathrm{M} \mathrm{HClO}_{4}$ electrolyte at a potential sweep rate of $20 \mathrm{mV} \mathrm{s}^{-1}$ on a) Pt/C TKK, b) Hollow PtNi/C and c) Sponge 
PtNi/C. Regions related to $H_{U P D}$ desorption and $\mathrm{CO}_{a d s}$ monolayer electrooxidation are coloured in blue and orange, respectively. In d), the overlap between $\mathrm{H}_{U P D}$ and $\mathrm{CO}_{\text {ads }}$ electrooxidation currents observed for the Sponge PtNi/C is coloured in purple. The dotted lines in a)-c) serve as guides to the eye.

In conclusion, by calculating the integrated charges for $\mathrm{H}_{\mathrm{UPD}}$ desorption and $\mathrm{CO}_{\text {ads }}$ monolayer electrooxidation on several $\mathrm{Pt}(\mathrm{Ni})$ catalysts featuring various chemical compositions, sizes, shapes and degrees of surface defectiveness, we have shown that distorted surfaces (i.e. containing local strain) feature $Q_{\mathrm{CO}} / 2 Q_{\mathrm{H}}$ charge ratios below 1 ( 0.94 in our case). Moreover, for structurally-disordered catalysts, this charge ratio varies almost linearly with the corresponding surface distortion values (derived from synchrotron X-ray measurements). Complementarily, and in agreement with former findings for 'Pt-skin' and 'Pt-skeleton' surfaces, $Q_{\mathrm{CO}} / 2 Q_{\mathrm{H}}$ charge ratio values close or above 1 have been found for structurallyordered nanocatalysts. We tentatively ascribe the decrease of the $Q_{\mathrm{CO}} / 2 Q_{\mathrm{H}}$ ratio to the formation of $\mathrm{OH}_{\text {ads }}$ species in the $\mathrm{H}_{\mathrm{UPD}}$ region on highly oxophilic catalytic sites fractionally present on distorted surfaces. Most importantly, the strong correlation between resourcedemanding synchrotron X-ray structural data and the simple electrochemical adsorption fingerprint reported herein provides the scientific community with a new, easily accessible and 
versatile tool for the in situ identification and semi-quantification of structural disorder in Ptbased surfaces, both in RDE setups and in an application-relevant PEMFC device. 
The Supporting Information is available free of charge on the ACS Publications website at

DOI:XXXX

Experimental details about the different materials synthesis, STEM/X-EDS measurements, estimation of the surface distortion (SD) descriptor via synchrotron WAXS and Rietveld refinement, RDE electrochemical characterizations, MEAs manufacturing and fuel call measurements. Supplementary Figures S1-S4 show typical $\mathrm{CO}_{\mathrm{ads}}$ stripping experiments and the electrical charge integration method used. Supplementary Figures S5-S6 show $\mathrm{CO}_{\text {ads }}$ stripping experiments measured in various liquid electrolytes (perchloric acid, sulphuric acid and methylsulfonic acid). Supplementary Figure S7 shows the negligible impact of CO exposure on the voltammogram features. Supplementary Figure S8 shows an extended $Q_{\mathrm{CO}} / 2 Q_{\mathrm{H}}-\mathrm{SD}$ trend including acid-treated materials. Supplementary Figure S9 presents the limited predictive power of the $Q_{\mathrm{CO}} / 2 Q_{\mathrm{H}}$ ratio toward ORR activity. Supplementary Tables S1S3 display all the numerical values regarding the materials chemical composition, particle size, crystallite size, surface distortion, $Q_{\mathrm{CO}} / 2 Q_{\mathrm{H}}$ ratio and specific activity for the ORR.

\author{
*E-mail: raphael.chattot@grenoble-inp.org \\ *E-mail: laetitia.dubau@lepmi.grenoble-inp.fr \\ Raphaël CHATTOT: 0000-0001-6169-530X
}


Isaac Martens: 0000-0001-8342-6629
Juan Herranz: 0000-0002-5805-6192
Jakub Drnec: 0000-0002-9520-1555
Frédéric Maillard: 0000-0002-6470-8900
Laetitia Dubau: 0000-0001-9520-1435
The authors declare no competing financial interest.

This work was performed within the framework of the Centre of Excellence of Multifunctional Architectured Materials 'CEMAM' $n^{\circ}$ ANR-10-LABX-44-01. The authors acknowledge financial support from the French National Research Agency (HOLLOW and BRIDGE projects). The authors are grateful to the groups of Prof. Dr. Peter Strasser from TU Berlin, Prof. Dr. Thomas J. Schmidt from the PSI and Prof. Dr. Alexander Eychmüller from TU Dresden for sharing their knowledge in various materials synthesis. 
(1) Katsounaros, I.; Cherevko, S.; Zeradjanin, A. R.; Mayrhofer, K. J. J. Oxygen Electrochemistry as a Cornerstone for Sustainable Energy Conversion. Angew. Chemie - Int. Ed. 2014, $53(1)$, 102-121.

(2) Stamenkovic, V. R.; Mun, B. S.; Arenz, M.; Mayrhofer, K. J. J.; Lucas, C. A.; Wang, G.; Ross, P. N.; Markovic, N. M. Trends in Electrocatalysis on Extended and Nanoscale PtBimetallic Alloy Surfaces. Nat. Mater. 2007, 6 (3), 241-247.

(3) Stamenkovic, V. R.; Fowler, B.; Mun, B. S.; Wang, G.; Ross, P. N.; Lucas, C. A.; Markovic, N. M. Improved Oxygen Reduction Activity on $\mathrm{Pt}_{3} \mathrm{Ni}(111)$ via Increased Surface Site Availability. Science 2007, 315(5811), 493-497.

(4) Blurton, K. F.; Greenberg, P.; Oswin, H. G.; Rutt, D. R. The Electrochemical Activity of Dispersed Platinum. J. Electrochem. Soc. 2007, 119(5), 559.

(5) Van Der Vliet, D. F.; Wang, C.; Li, D.; Paulikas, A. P.; Greeley, J.; Rankin, R. B.; Strmcnik, D.; Tripkovic, D.; Markovic, N. M.; Stamenkovic, V. R. Unique Electrochemical Adsorption Properties of Pt-Skin Surfaces. Angew. Chemie - Int. Ed. 2012, 51 (13), 3139-3142.

(6) Henning, S.; Kühn, L.; Herranz, J.; Durst, J.; Binninger, T.; Nachtegaal, M.; Werheid, M.; Liu, W.; Adam, M.; Kaskel, S.; et al. Pt-Ni Aerogels as Unsupported Electrocatalysts for the Oxygen Reduction Reaction. J. Electrochem. Soc. 2016, 163 (9), F998-F1003.

(7) Shi, Q.; Zhu, C.; Zhong, H.; Su, D.; Li, N.; Engelhard, M. H.; Xia, H.; Zhang, Q.; Feng, S.; Beckman, S. P.; et al. Nanovoid Incorporated $\mathrm{Ir}_{\mathrm{x}} \mathrm{Cu}$ Metallic Aerogels for Oxygen Evolution Reaction Catalysis. ACS Energy Lett. 2018, 3 (9), 2038-2044.

(8) Li, M.; Zhao, Z.; Cheng, T.; Fortunelli, A.; Chen, C. Y.; Yu, R.; Zhang, Q.; Gu, L.; Merinov, B. V.; Lin, Z.; et al. Ultrafine Jagged Platinum Nanowires Enable Ultrahigh Mass Activity for the Oxygen Reduction Reaction. Science 2016, 354 (6318), 14141419.

(9) Alia, S. M.; Ngo, C.; Shulda, S.; Ha, M. A.; Dameron, A. A.; Weker, J. N.; Neyerlin, K. C.; Kocha, S. S.; Pylypenko, S.; Pivovar, B. S. Exceptional Oxygen Reduction Reaction Activity and Durability of Platinum-Nickel Nanowires through Synthesis and PostTreatment Optimization. ACS Omega 2017, 2 (4), 1408-1418.

(10) Van Der Vliet, D. F.; Wang, C.; Tripkovic, D.; Strmcnik, D.; Zhang, X. F.; Debe, M. K.; Atanasoski, R. T.; Markovic, N. M.; Stamenkovic, V. R. Mesostructured Thin Films as Electrocatalysts with Tunable Composition and Surface Morphology. Nat. Mater. 2012, 
$11(12), 1051-1058$.

(11) Bae, S. J.; Yoo, S. J.; Lim, Y.; Kim, S.; Lim, Y.; Choi, J.; Nahm, K. S.; Hwang, S. J.; Lim, T.-H.; Kim, S.-K.; et al. Facile Preparation of Carbon-Supported PtNi Hollow Nanoparticles with High Electrochemical Performance. J. Mater. Chem. 2012, 22 (18), 8820.

(12) Snyder, J.; Fujita, T.; Chen, M. W.; Erlebacher, J. Oxygen Reduction in Nanoporous Metal-Ionic Liquid Composite Electrocatalysts. Nat. Mater. 2010, 9(11), 904-907.

(13) Dubau, L.; Asset, T.; Chattot, R.; Bonnaud, C.; Vanpeene, V.; Nelayah, J.; Maillard, F. Tuning the Performance and the Stability of Porous Hollow PtNi/C Nanostructures for the Oxygen Reduction Reaction. ACS Catal. 2015, 5 (9), 5333-5341.

(14) Chattot, R.; Asset, T.; Bordet, P.; Drnec, J.; Dubau, L.; Maillard, F. Beyond Strain and Ligand Effects: Microstrain-Induced Enhancement of the Oxygen Reduction Reaction Kinetics on Various PtNi/C Nanostructures. ACS Catal. 2017, 7, 398-408.

(15) Henning, S.; Herranz, J.; Ishikawa, H.; Kim, B. J.; Abbott, D.; Kühn, L.; Eychmüller, A.; Schmidt, T. J. Durability of Unsupported Pt-Ni Aerogels in PEFC Cathodes. J. Electrochem. Soc. 2017, 164 (12), F1136-F1141.

(16) Henning, S.; Ishikawa, H.; Kühn, L.; Herranz, J.; Müller, E.; Eychmüller, A.; Schmidt, T. J. Unsupported Pt-Ni Aerogels with Enhanced High Current Performance and Durability in Fuel Cell Cathodes. Angew. Chemie - Int. Ed. 2017, 56(36), 10707-10710.

(17) Luo, M.; Sun, Y.; Zhang, X.; Qin, Y.; Li, M.; Li, Y.; Li, C.; Yang, Y.; Wang, L.; Gao, P.; et al. Stable High-Index Faceted Pt Skin on Zigzag-Like PtFe Nanowires Enhances Oxygen Reduction Catalysis. Adv. Mater. 2018, 30(10), 1-9.

(18) Dubau, L.; Nelayah, J.; Moldovan, S.; Ersen, O.; Bordet, P.; Drnec, J.; Asset, T.; Chattot, R.; Maillard, F. Defects Do Catalysis: CO Monolayer Oxidation and Oxygen Reduction Reaction on Hollow PtNi/C Nanoparticles. ACS Catal. 2016, 6 (7), 4673-4684.

(19) Le Bacq, O.; Pasturel, A.; Chattot, R.; Previdello, B.; Nelayah, J.; Asset, T.; Dubau, L.; Maillard, F. Effect of Atomic Vacancies on the Structure and the Electrocatalytic Activity of Pt-Rich/C Nanoparticles: A Combined Experimental and Density Functional Theory Study. ChemCatChem 2017, 9 (12), 2324-2338.

(20) Alia, S. M.; Pylypenko, S.; Neyerlin, K. C.; Kocha, S. S.; Pivovar, B. S. Nickel Nanowire Oxidation and Its Effect on Platinum Galvanic Displacement and Methanol Oxidation. ECS Trans. 2014, 64 (3), 89-95. 
(21) Xiong, Z.; Li, S.; Xu, H.; Zhang, K.; Yan, B.; Du, Y. Newly Designed Ternary Metallic PtPdBi Hollow Catalyst with High Performance for Methanol and Ethanol Oxidation. Catalysts 2017, 7(7), 208.

(22) Mao, J.; Chen, W.; He, D.; Wan, J.; Pei, J.; Dong, J.; Wang, Y.; An, P.; Jin, Z.; Xing, W.; et al. Design of Ultrathin Pt-Mo-Ni Nanowire Catalysts for Ethanol Electrooxidation. Sci. Adv. 2017, 3, 1-10.

(23) Zhao, S.; Li, M.; Han, M.; Xu, D.; Yang, J.; Lin, Y.; Shi, N. E.; Lu, Y.; Yang, R.; Liu, B.; et al. Defect-Rich Ni3FeN Nanocrystals Anchored on N-Doped Graphene for Enhanced Electrocatalytic Oxygen Evolution. Adv. Funct. Mater. 2017, $28(18), 1706018$.

(24) Wang, P.; Jiang, K.; Wang, G.; Yao, J.; Huang, X. Phase and Interface Engineering of Platinum-Nickel Nanowires for Efficient Electrochemical Hydrogen Evolution. Angew. Chemie - Int. Ed. 2016, 55(41), 12859-12863.

(25) Dickens, C. F.; Nørskov, J. K. A Theoretical Investigation into the Role of Surface Defects for Oxygen Evolution on $\mathrm{RuO}_{2}$. J. Phys. Chem. C2017, $121(34), 18516-18524$.

(26) Calle-Vallejo, F.; Tymoczko, J.; Colic, V.; Quang, H. V.; Pohl, M. D.; Morgenstern, K.; Loffreda, D.; Sautet, P.; Schuhmann, W.; Bandarenka, A. S. Finding Optimal Surface Sites on Heterogeneous Catalysts by Counting Nearest Neighbors. Science 2015, 350 (6257), 185-190.

(27) Calle-Vallejo, F.; Pohl, M. D.; Bandarenka, A. S. Quantitative Coordination-Activity Relations for the Design of Enhanced Pt Catalysts for CO Electro-Oxidation. ACS Catal. 2017, $7(7), 4355-4359$.

(28) Dubau, L.; Nelayah, J.; Asset, T.; Chattot, R.; Maillard, F. Implementing Structural Disorder as a Promising Direction for Improving the Stability of PtNi/C Nanoparticles. ACS Catal. 2017, 7(4), 3072-3081.

(29) Chattot, R.; Bacq, O. Le; Beermann, V.; Kühl, S.; Herranz, J.; Henning, S.; Kühn, L.; Asset, T.; Guétaz, L.; Renou, G.; et al. Surface Distortion as a Unifying Concept and Descriptor in Oxygen Reduction Reaction Electrocatalysis. Nat. Mater. 2018, 17 (9), 827-833.

(30) Haag, S. T.; Richard, M. I.; Welzel, U.; Favre-Nicolin, V.; Balmes, O.; Richter, G.; Mittemeijer, E. J.; Thomas, O. Concentration and Strain Fields inside a Ag/Au CoreShell Nanowire Studied by Coherent X-Ray Diffraction. Nano Lett. 2013, 13 (5), 18831889. 
(31) Wang, Y.; Zhang, W. Mapping the Strain Distribution within Embedded Nanoparticles via Geometrical Phase Analysis. Micron 2019, 125 (July), 102715.

(32) Daio, T.; Staykov, A.; Guo, L.; Liu, J.; Tanaka, M.; Matthew Lyth, S.; Sasaki, K. Lattice Strain Mapping of Platinum Nanoparticles on Carbon and $\mathrm{SnO}_{2}$ Supports. Sci. Rep. 2015, 5, 1-10.

(33) Yang, Y.; Chen, C. C.; Scott, M. C.; Ophus, C.; Xu, R.; Pryor, A.; Wu, L.; Sun, F.; Theis, W.; Zhou, J.; et al. Deciphering Chemical Order/Disorder and Material Properties at the Single-Atom Level. Nature 2017, 542 (7639), 75-79.

(34) Iannielo, R.; Schmidt, V. M.; Stimming, U.; Stumper, J.; Wallau, A. CO Adsorption and Oxydation on Pt and Pt-Ru Alloys: Dependance on Substrate Composition. Electrochim. Acta 1994, 39, 1863.

(35) Maillard, F.; Eikerling, M.; Cherstiouk, O. V; Schreier, S.; Savinova, E.; Stimming, U. Size Effects on Reactivity of Pt Nanoparticles in CO Monolayer Oxidation: The Role of Surface Mobility. Faraday Discuss. 2004, 125, 357-377.

(36) Maillard, F.; Schreier, S.; Hanzlik, M.; Savinova, E. R.; Weinkauf, S.; Stimming, U. Influence of Particle Agglomeration on the Catalytic Activity of Carbon-Supported $\mathrm{Pt}$ Nanoparticles in CO Monolayer Oxidation. Phys. Chem. Chem. Phys. 2005, 7(2), 385393.

(37) Urchaga, P.; Baranton, S.; Coutanceau, C.; Jerkiewicz, G. Electro-Oxidation of CO Chem on Pt Nanosurfaces: Solution of the Peak Multiplicity Puzzle. Langmuir 2012, 28 (7), 3658-3663.

(38) Bandarenka, A. S.; Varela, A. S.; Karamad, M.; Calle-Vallejo, F.; Bech, L.; PerezAlonso, F. J.; Rossmeisl, J.; Stephens, I. E. L.; Chorkendorff, I. Design of an Active Site towards Optimal Electrocatalysis: Overlayers, Surface Alloys and near-Surface Alloys of Cu/Pt(111). Angew. Chemie - Int. Ed. 2012, 51 (47), 11845-11848.

(39) Feibelman, P. J.; Hammer, B.; Nørskov, J. K.; Wagner, F.; Scheffler, M.; Stumpf, R.; Watwe, R.; Dumesic, J. The CO/Pt(111) Puzzle. J. Phys. Chem. B 2001, 105 (18), 4018-4025.

(40) Farias, M. J. S.; Busó-Rogero, C.; Vidal-Iglesias, F. J.; Solla-Gullón, J.; Camara, G. A.; Feliu, J. M. Mobility and Oxidation of Adsorbed $\mathrm{CO}$ on Shape-Controlled Pt Nanoparticles in Acidic Medium. Langmuir 2017, 33 (4), 865-871.

(41) Hoster, H. E.; Alves, O. B.; Koper, M. T. M. Tuning Adsorption via Strain and Vertical 
Ligand Effects. ChemPhysChem 2010, 11 (7), 1518-1524.

(42) El Jawad, M. K.; Gilles, B.; Maillard, F. Structure and Surface Reactivity of Ultra-Thin $\mathrm{Pt} / \mathrm{W}(111)$ Films. Electrocatalysis 2015, 6(4), 398-404.

(43) Markovic, N. M.; Ross Jr., P. N. Surface Science Studies of Model Fuel Cell Electrocatalysts. Surf. Sci. Rep. 2002, 45(4-6), 117-229.

(44) Takahashi, I.; Kocha, S. S. Examination of the Activity and Durability of PEMFC Catalysts in Liquid Electrolytes. J. Power Sources 2010, 195(19), 6312-6322.

(45) Shinozaki, K.; Zack, J. W.; Richards, R. M.; Pivovar, B. S.; Kocha, S. S. Oxygen Reduction Reaction Measurements on Platinum Electrocatalysts Utilizing Rotating Disk Electrode Technique: I. Impact of Impurities, Measurement Protocols and Applied Corrections. J. Electrochem. Soc. 2015, 162(10), F1144-F1158.

(46) Shinozaki, K.; Zack, J. W.; Richards, R. M.; Pivovar, B. S.; Kocha, S. S. Oxygen Reduction Reaction Measurements on Platinum Electrocatalysts Utilizing Rotating Disk Electrode Technique: II. Influence of Ink Formulation, Catalyst Layer Uniformity and Thickness. J. Electrochem. Soc. 2015, 162 (12), F1384-F1396.

(47) Garsany, Y.; Baturina, O. a; Swider-Lyons, K. E.; Kocha, S. S. Experimental Methods for Quantifying the Activity of Platinum Electrocatalysts for the Oxygen Reduction Reaction. Anal. Chem. 2010, 82 (15), 6321-6328.

(48) Garsany, Y.; Singer, I. L.; Swider-Lyons, K. E. Impact of Film Drying Procedures on RDE Characterization of Pt/VC Electrocatalysts. J. Electroanal. Chem. 2011, 662 (2), 396-406.

(49) Mayrhofer, K. J. J.; Strmcnik, D.; Blizanac, B. B.; Stamenkovic, V.; Arenz, M.; Markovic, N. M. Measurement of Oxygen Reduction Activities via the Rotating Disc Electrode Method: From Pt Model Surfaces to Carbon-Supported High Surface Area Catalysts. Electrochim. Acta 2008, 53 (7), 3181-3188.

(50) Schulenburg, H.; Durst, J.; Müller, E.; Wokaun, A.; Scherer, G. G. Real Surface Area Measurements of $\mathrm{Pt}_{3} \mathrm{Co} / \mathrm{C}$ Catalysts. J. Electroanal. Chem. 2010, 642 (1), 52-60.

(51) Cui, C.; Gan, L.; Heggen, M.; Rudi, S.; Strasser, P. Compositional Segregation in Shaped Pt Alloy Nanoparticles and Their Structural Behaviour during Electrocatalysis. Nat. Mater. 2013, 12(8), 765-771.

(52) Niu, Z.; Becknell, N.; Yu, Y.; Kim, D.; Chen, C.; Kornienko, N.; Somorjai, G. A.; Yang, 
P. Anisotropic Phase Segregation and Migration of Pt in Nanocrystals En Route to Nanoframe Catalysts. Nat. Mater. 2016, 15(11), 1188-1194.

(53) Chen, Q. S.; Solla-Gullón, J.; Sun, S. G.; Feliu, J. M. The Potential of Zero Total Charge of Pt Nanoparticles and Polycrystalline Electrodes with Different Surface Structure: The Role of Anion Adsorption in Fundamental Electrocatalysis. Electrochim. Acta 2010, 55 (27), 7982-7994.

(54) Greeley, J.; Mavrikakis, M. Near-Surface Alloys for Hydrogen Fuel Cell Applications. Catal. Today 2006, $111(1-2), 52-58$.

(55) Humbert, M. P.; Chen, J. G. Correlating Hydrogenation Activity with Binding Energies of Hydrogen and Cyclohexene on $\mathrm{M} / \mathrm{Pt}(111)(\mathrm{M}=\mathrm{Fe}, \mathrm{Co}, \mathrm{Ni}, \mathrm{Cu})$ Bimetallic Surfaces. J. Catal. 2008, $257(2)$, 297-306.

(56) Marichev, V. A. Reversibility of Platinum Voltammograms in Aqueous Electrolytes and Ionic Product of Water. Electrochim. Acta 2008, 53 (27), 7952-7960.

(57) Van Der Niet, M. J. T. C.; Garcia-Araez, N.; Hernández, J.; Feliu, J. M.; Koper, M. T. M. Water Dissociation on Well-Defined Platinum Surfaces: The Electrochemical Perspective. Catal. Today 2013, 202 (1), 105-113.

(58) Janik, M. J.; McCrum, I. T.; Koper, M. T. M. On the Presence of Surface Bound Hydroxyl Species on Polycrystalline Pt Electrodes in the "Hydrogen Potential Region" (0 to $0.4 \mathrm{~V}$ RHE). J. Catal. 2018, 367, 332-337.

(59) Tanaka, H.; Sugawara, S.; Shinohara, K.; Ueno, T.; Suzuki, S.; Hoshi, N.; Nakamura, M. Infrared Reflection Absorption Spectroscopy of $\mathrm{OH}$ Adsorption on the Low Index Planes of Pt. Electrocatalysis 2015, 6 (3), 295-299.

(60) Garcia-Araez, N.; Climent, V.; Feliu, J. M. Analysis of Temperature Effects on Hydrogen and $\mathrm{OH}$ Adsorption on $\mathrm{Pt}(111), \operatorname{Pt}(100)$ and $\mathrm{Pt}(110)$ by Means of Gibbs Thermodynamics. J. Electroanal. Chem. 2010, 649(1-2), 69-82.

(61) Gilman, S. The Mechanism of Electrochemical Oxidation of Carbon Monoxide and Methanol on Platinum . I. Carbon Monoxide Adsorption and Desorption and Simultaneous Oxidation of the Platinum Surface at Constant Potential. J. Phys. Chem. 1963, $67(2), 1905-1989$.

(62) Huang, Y. F.; Kooyman, P. J.; Koper, M. T. M. Intermediate Stages of Electrochemical Oxidation of Single-Crystalline Platinum Revealed by in Situ Raman Spectroscopy. Nat. Commun. 2016, 7, 1-7. 


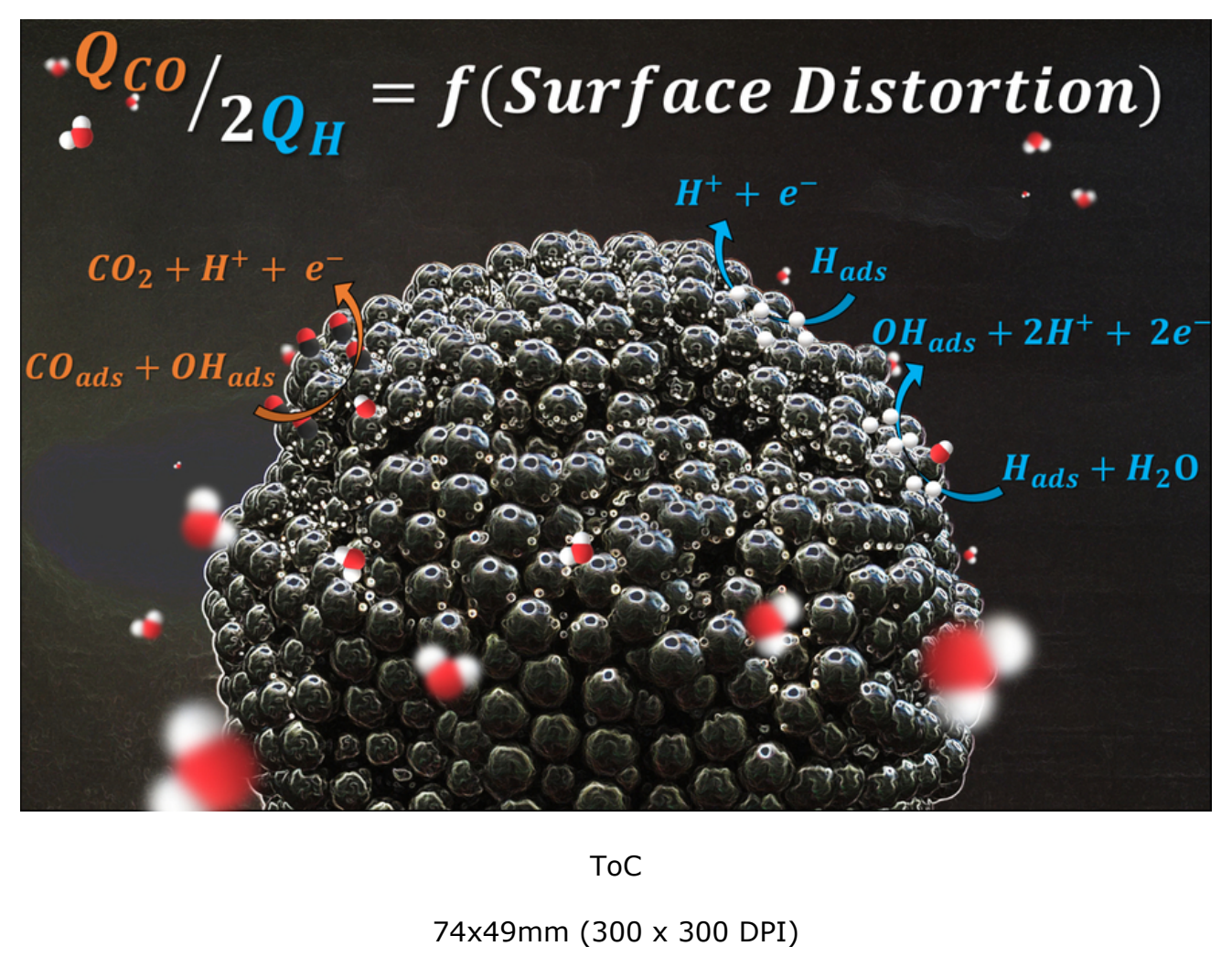

ACS Paragon Plus Environment 


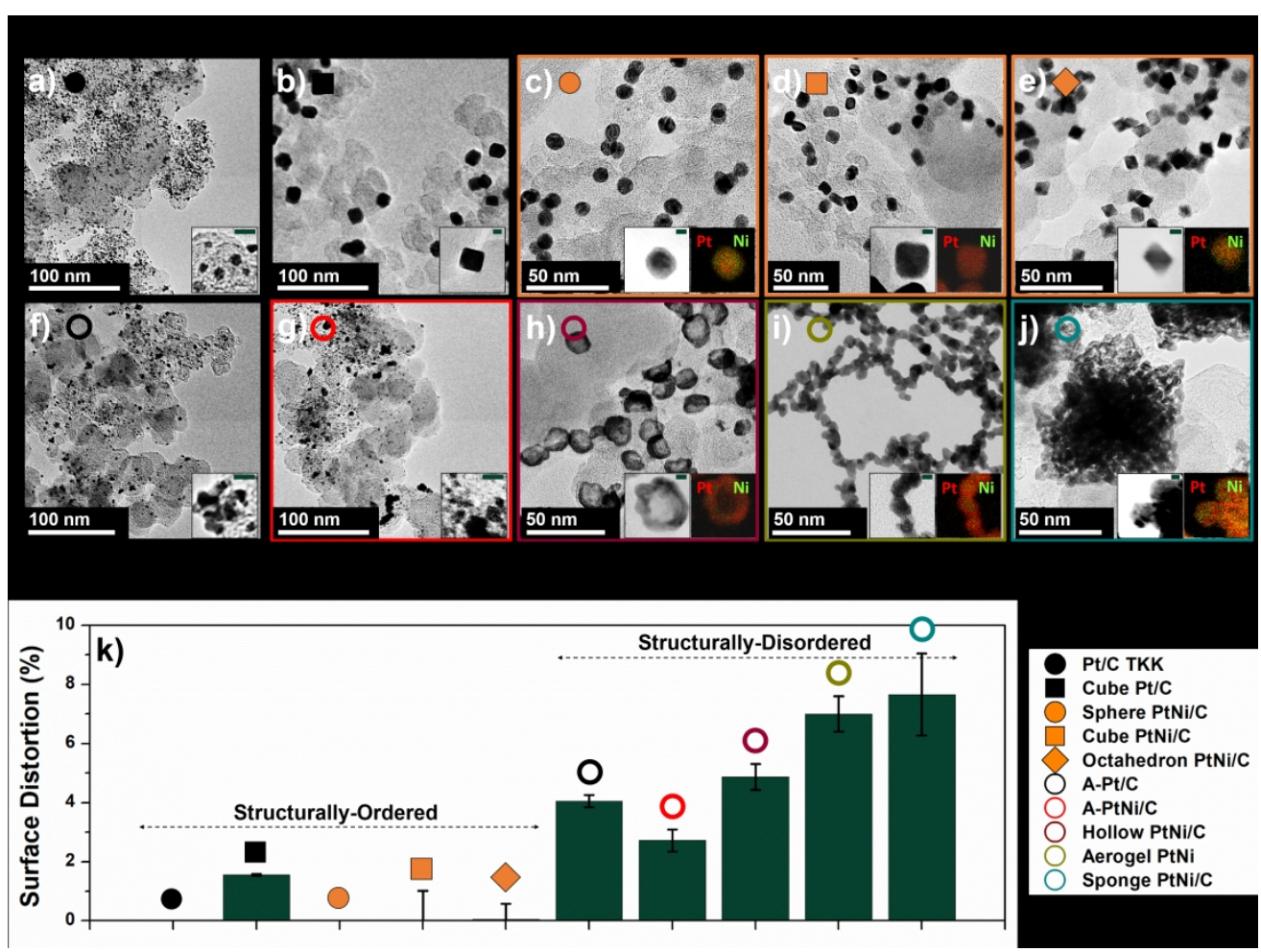

Figure 1. Morphology and structure of the nanocatalysts used in this study. TEM images of a)-e) structurally-ordered and f)-j) structurally-disordered catalysts, along with k) the corresponding Surface Distortion (SD) values derived from Rietveld refinement of synchrotron WAXS patterns. The error bars refer to the standard deviations. Inserts in a), b), f) and g) show high magnification TEM images and inserts in $\mathrm{c}$ ),

d), e), h), i) and j) display STEM/X-EDS elemental maps in which Pt and Ni atoms are displayed in red/green, respectively. In the inserts, the scale bars stand for $5 \mathrm{~nm}$. 


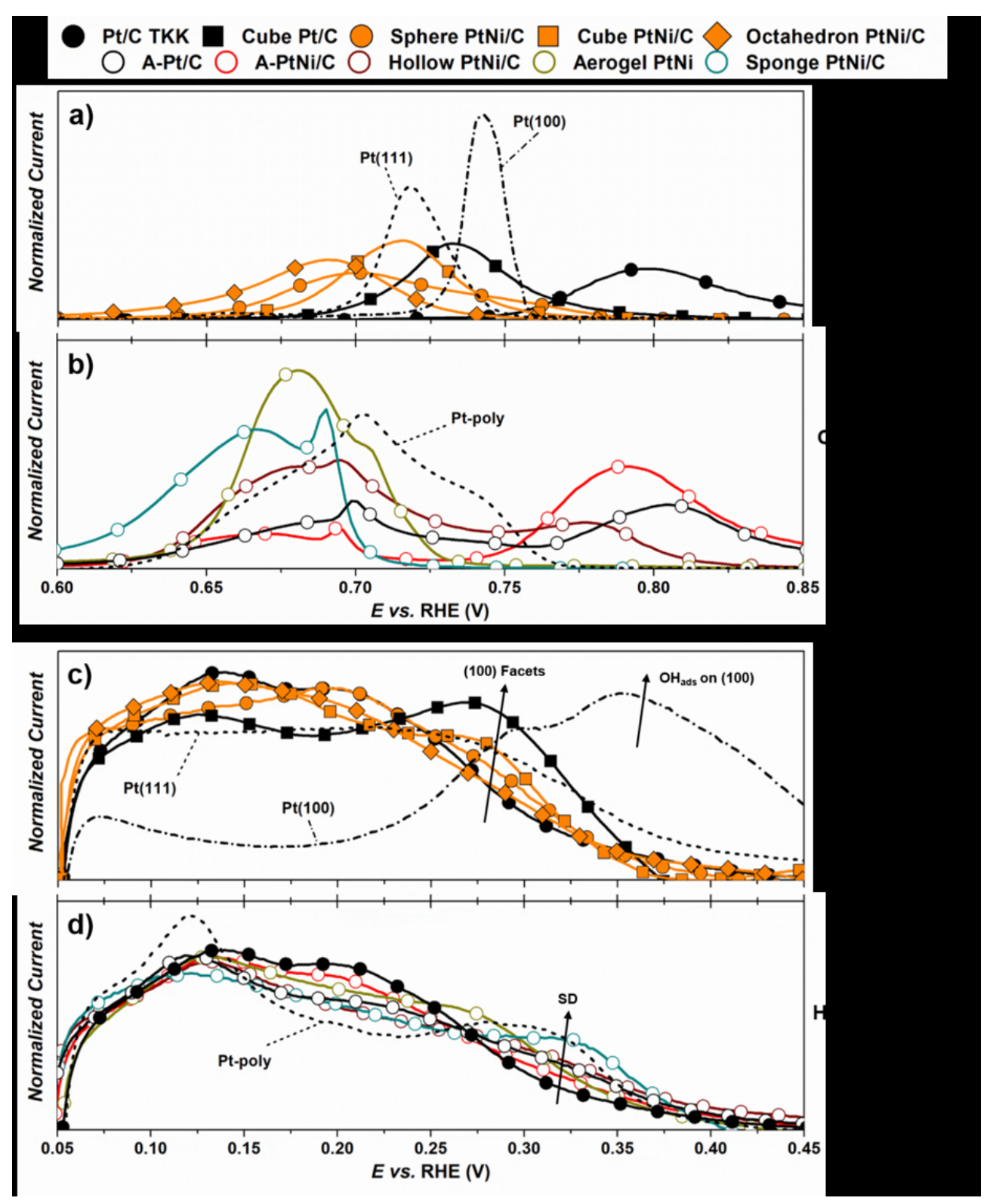

Figure 2. Background-subtracted $\mathrm{CO}_{\text {ads }}$ stripping and $\mathrm{H}_{\text {ads }}$ desorption voltammograms recorded on structurally-ordered and structurally-disordered Pt and PtNi nanocatalysts. The $\mathrm{CO}_{\text {ads }}$ stripping curves are shown in a) and b) and the $\mathrm{H}_{\text {ads }}$ desorption curves in c) and d) for structurally-ordered and structurally-disordered catalysts, respectively. All curves were recorded in Ar-saturated $0.1 \mathrm{M} \mathrm{HClO}_{4}$ electrolyte at a potential sweep rate of $20 \mathrm{mV} \mathrm{s}^{-1}$ The labelled dotted lines represent cyclic voltammograms of extended Pt surfaces. The currents in a)-b) and c)-d) are normalized by the $\mathrm{CO}_{\text {ads }}$ electrooxidation coulometry $\left(Q_{C O}\right)$ and the $\mathrm{H}_{\text {ads }}$ desorption charge coulometry $\left(Q_{H}\right)$, respectively. 
Figure 3. Probing surface distortion using the $Q_{\mathbf{c o}} / 2 Q_{H}$ ratio in both liquid electrolyte and a fuel cell device. Whereas $Q_{C O} / 2 Q_{H}=1.5$ values indicate the presence of a 'Pt-skin' surface ${ }^{5}, Q_{C O} / 2 Q_{H}$ values $<0.92$ reflect 'Pt distorted' surfaces. The region in-between those two is usually assigned to 'Pt-skeleton' surfaces ${ }^{5}$. The $Q_{C O}$ and $Q_{H}$ values were extracted from $\mathrm{CO}_{\text {ads }}$ stripping voltammograms measured in a 5 $\mathrm{cm}^{2}$ PEM fuel cell (small symbols) or in $0.1 \mathrm{M} \mathrm{HClO}_{4}$ (large symbols) and the SD values using ex situ synchrotron WAXS patterns and the methodology formerly introduced in Ref 29 . The error bars represent the standard deviations of these quantities. Note that some of the PEM fuel cell measurements were performed on materials' batches different from those used for the RDE tests. All measurements have been performed at $25^{\circ} \mathrm{C}$. The inset surfaces drawings depict Pt and $\mathrm{Ni}$ atoms as green and blue spheres, respectively. The dashed lines serve as guides to the eye.

$$
241 \times 171 \mathrm{~mm}(150 \times 150 \mathrm{DPI})
$$



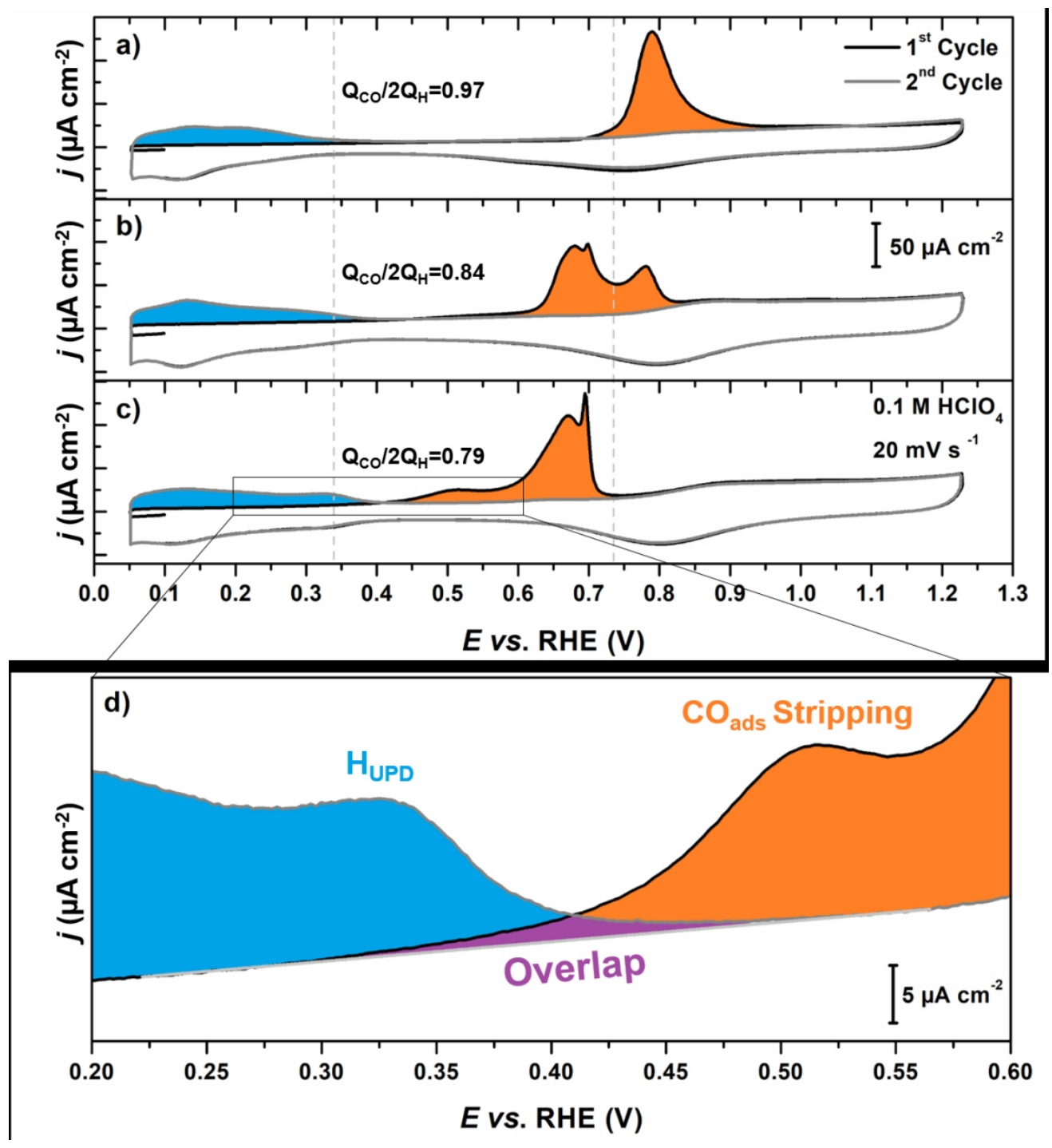

Figure 4. Influence of surface distortion on the shape of base and $\mathrm{CO}_{\text {ads }}$ monolayer stripping voltammograms. First and second cycles of the $\mathrm{CO}_{\text {ads }}$ stripping experiment recorded in Ar-saturated $0.1 \mathrm{M}$ $\mathrm{HClO}_{4}$ electrolyte at a potential sweep rate of $20 \mathrm{mV} \mathrm{s}^{-1}$. on a) Pt/C TKK, b) Hollow PtNi/C and c) Sponge $\mathrm{PtNi} / \mathrm{C}$. Regions related to $\mathrm{H}_{U P D}$ desorption and $\mathrm{CO}_{\text {ads }}$ monolayer electrooxidation are coloured in blue and orange, respectively. In d), the overlap between $\mathrm{H}_{U P D}$ and $\mathrm{CO}_{\text {ads }}$ electrooxidation currents for the Sponge $\mathrm{PtNi} / \mathrm{C}$ is coloured in purple. The dotted lines in a)-c) serve as a guide to the eye.

\section{$228 \times 248 \mathrm{~mm}(150 \times 150 \mathrm{DPI})$}

